N $73 \quad 30741$

NASA TECHNICAL MEMORANDUM

NASA TM X-68284

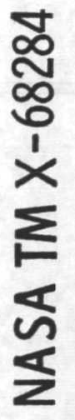

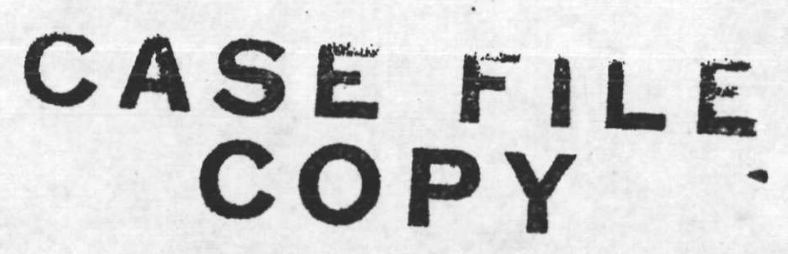

A 9700-HOUR DURAB ILITY TEST OF A

FIVE CENTIMETER DIAMETER ION THRUSTER

by S. Nakanishi and R. C. Finke

Lewis Research Center

- Cleveland, Ohio 44135

TECHNICAL PAPER proposed for presentation at Propulsion Specialist Conference sponsored by the American Institute of Aeronautics and Astronautics Lake Tahoe, Nevada, October 29-November 2, 1973 


\section{A 9700-HOUR DURABILITY TEST OF A FIVE CENTTMETER DIAMETER ION THRUSTER}

S. Nakanishi and R. C. Finke

National Aeronautics and Space Administration

Lewis Research Center

cleveland, Ohio

\section{Abstract}

A modified Hughes SIT-5 thruster has been 1ife-tested at the Lewis Research Center. The final 2700 hours of the test are described with a charted history of thruster operating parameters and off-normal events. Performance and operating characteristics were nearly constant throughout the test except for neutralizer heater power requirements and accelerator drain current. A postshutdown inspection revealed sputter erosion of ion chamber components and component flaking of sputtered metal. Several flakes caused beamlet divergence and anomalous grid erosion, causing the test to be terminated. All sputter erosion sources have been identified and promising sputter resistant components are currently being evaluated.

\section{Introduction}

Electron bombardment ion thrusters have potential application for spacecraft attitude control and station-keeping. $(1,2)$ Primary requirements for such thrusters are reliability and durability over many thousands of operating hours. $(3,4)$ Thrust vectoring capability is also desirable for many applications.

A 5-cm diameter thrust vectorable structurally integrated ion thruster (SIT-5) system was designed and developed by the Hughes Research Laboratories under NASA Contracts NAS3-14129 and NAS3-14058. $(5,6)$ A modified SIT-5 thruster of a first generation design has been tested at the Lewis Research Center. The purpose of the test was to determine the ultimate life of the thruster and to pinpoint problem areas not discernible in short term tests.

This paper presents the operational results spanning approximately the final 2700 hours of the durability test. The initial 2000 hours of the test with results of inspection and the ensuing 5000 hours of continuous operation have been reported previously. $(7,8)$ The final segment of the 9715 hour test is described in a detailed operational history of several thruster and neutralizer parameters. Performance profiles and thruster characteristics mapped at 6130 and 9030 hours will be compared. Some of the findings of the postshutdown inspection are included.

\section{Apparatus and Procedure}

A photograph of the modified SIT-5 thruster installation is shown in figure 1 . The specific modifications described in detail elsewhere $(7,8)$ included removal of the propellant reservoir, repositioning of the neutralizer, and change of accelerator optics. The electrostatic thrust vector grid was installed after the thruster had operated 2027 hours with a translating-screen type vector grid. At that time, the thruster was disassembled for photographic documentation. No refurbishing or repairs were made which would have compromised the legitimate continuation of the test and accu- mulation of test hours on the thruster.

Figure 2 shows an interior view of the vertical vacuum tank before the test. The tank is

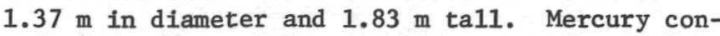
tained in the stainless steel pan was frozen by liquid nitrogen flowing through coils brazed to radial copper struts attached to the bottom of the pan. A cylindrical cooling coil brazed to vertical copper strips formed the $\mathrm{LN}_{2}$ cryowall which extended along the vertical wall of the tank.

The accelerator grid of the thruster was approximately $75 \mathrm{~cm}$ above the frozen mercury target when installed. To prevent backsputtering of condensible conductive material upon the thruster, a set of nonmetallic $\left(50 \% \mathrm{Al}_{2} \mathrm{O}_{3}, 50 \% \mathrm{SiO}_{2}\right)$ baffles were installed. No metallic surface other than the mercury target intercepted the line of sight of the thruster ion beam. With the target frozen and the cryowall at liquid nitrogen temperature, the ultimate tank pressure reached the mid $10^{-7}$ torr range. With the thruster in operation, the pressure rose to about $1 \times 10^{-6}$ torr.

Details of the electrical system and test procedures are described elsewhere. (7) An automatic digital data acquisition system recorded thruster data at clocked intervals. A protective control system designed to shut down the thruster in the event of abnormal thruster or test facility conditions allowed unattended operation around the clock. The thruster was operated open-looped at nominally fixed conditions except for minor day-today adjustments. The ion chamber and neutralizer propellant flow rates were held at about $34 \mathrm{~mA}$ and $2.2 \mathrm{~mA} \mathrm{Hg}^{+}$, respectively, throughout the test. Performance mapping data were obtained at approximately 1000 hour intervals. A four-channel stripchart recorder was used to chart the neutralizer parameters continuous1y.

\section{$\underline{\text { Results and Discussion }}$}

\section{History of Test}

A history of the test from 7000 thruster hours to the end at 9715 hours is shown in figure 3 . The electrostatic vector grid was installed at 2027 thruster hours so that the number of hours on the grid is less than the thruster operating time by that amount. The four parameters charted were those most subject to change with time. As described previously, (8) other thruster parameters either remained nearly constant throughout the test or were adjusted to fixed operating values.

The accelerator drain current shown in figure 3(a) was about $0.09 \mathrm{~mA}$ from 2027 to 8000 thruster hours. From 8000 to 9500 hours the drain current remained at about $0.10 \mathrm{~mA}$ then suddenly increased to more than $0.20 \mathrm{~mA}$. Details of the final 270 hours of the test when numerous grid shorts occurred will be shown later. 
The cathode keeper voltage (fig. 3(b)) was constant to the end of the test at a value which prevailed from about 4000 hours. (8) Actually, the cathode keeper voltage first attained an operating level of $12-13$ volts as early as 400 hours into the test. The voltage subsequently rose to about 15 volts and gradually dropped to 12.5 volts by 4000 hours. No heater power was applied to the cathode except during startups.

The neutralizer keeper voltage and floating potential plotted in figures 3 (c) and (d) gradually rose with time. The irregular variations in these parameters were induced primarily by the changes in neutralizer heater power made during the test to stabilize neutralizer operation. Continuous strip chart records of neutralizer parameters to be presented later will show the nature of some neutralizer transients.

A consistent trend associated with neutralizer heater power can be seen in figure 3(c). Increasing heater power decreased the keeper voltage and floating potential. The decrease was followed by a gradual rise at approximately the same rate as the overall average rise with time. (8) This rise rate was about 1 volt per 1000 hours of operation, and it occurred even in the early hours of the test when heater power was 3 watts or less. The conclusion is that the mechanism causing the rise in keeper voltage was not entirely dependent on heater power and neutralizer temperature.

Noted on the test history are four types of recurrent abnormal events. Neutralizer outage precluded beam current operation because of highly negative neutralizer floating potential, but the protective control system shut off on $1 y$ the ion chamber discharge and the accelerating potentials. The cathode was permitted to continue operating in order to facilitate restarts.

High neutralizer floating potential also occurred without a neutralizer outage. This abnormal condition was rare in the first 7000 hours of test. It was especially numerous between 7100 and 7800 hours but nonexistent thereafter. The cause of these occurrences is not known. An excerpt from the continuous strip chart record of neutralizer parameters will be presented later to show details of this abnormal condition.

Shorting between vector grid elements occurred four times between 8000 and 9000 hours. These shorts occurred at a rate of 2 per 1000 hours of operation between 6000 and 7000 hours but were nonexistent prior to that period.

Screen to accelerator shorts were less numerous although one had occurred as early as 5000 hours into the test. In all instances, the shorts were cleared successfully either by application of vectoring voltage or by a capacitor discharge. A capacitor discharge usually quenched the neutralizer (in a manner similar to events early in the test(7) before installation of inductive ballasts in the high voltage circuits).

Terminal history. A history of the final segment of the durability test is shown in figure 4 to an expanded time scale. An uneventful 110-hour segment between 9580 and 9690 hours has been omitted for brevity.
The drain current, neutralizer keeper current, and neutralizer floating potential only are shown because no long-term trends in ion chamber parameters were discernible in this short time span. Thruster shutdowns occurred in close succession at 9518,9526 , and 9534 hours because of screenaccelerator shorts. The accelerator drain current (fig. 4 (a)) increased about $0.05 \mathrm{~mA}$ after each of the first two events. After the third screenaccelerator short was cleared, the drain-current dropped $0.07 \mathrm{~mA}$. It is believed that flakes of sputtered metal shed from ion chamber surfaces were defocusing the ions passing through partially blocked screen apertures. At worst, the first of grid element failures may have occurred at this point in the test. During the final 181 hours of the test, only one neutralizer-outage event occurred. The accelerator drain current continued to fluctuate with a gradual decline in the mean level. The test ended when a vector grid element cut through by a defocused beamlet dropped against the ground screen mask to cause a permanent short.

The neutralizer keeper current and floating potential are shown in figures $4(\mathrm{~b})$ and (c). The thruster shutdown at 9518 hours was preceded by two hours of unsteady neutralizer operation. The continuous strip chart record showed that at 9516 hours, the neutralizer keeper current dropped to $0.2 \mathrm{~A}$ and the vaporizer temperature dropped $17^{\circ} \mathrm{C}$. The neutralizer keeper voltage and floating potential increased about 10 volts and contained fluctuations varying in amplitude from 1 to 5 volts. There was no apparent connection between the neutralizer disturbances and the thruster shutdown at 9518 hours. Subsequent shutdowns caused by screenaccelerator shorts occurred during normal neutralizer operation. A neutralizer outage occurred at 9555 hours. From that point to the end of test the neutralizer operated at nearly constant conditions without interruption.

Neutralizer transients. A selected portion of the continuous strip chart recording of neutralizer parameters is shown in figure 5. Each division along the paper travel corresponds to 3.75 minutes. The four channels from left to right are neutralizer floating potential $\times 0.1 \mathrm{~V}$, neutralizer keeper voltage $\times 0.1 \mathrm{~V}$, neutralizer keeper current $\times 10 \mathrm{~A}$, and neutralizer vaporizer temperature (chromel-alume1 thermocouple, MV above $65.6^{\circ} \mathrm{C}$ ). The operating time in hours is noted along the left margin.

The abnormal condition which occurred at about 7666 hours was a series of high floating potential spikes which did not persist long enough to activate the protective control circuit. The relative time positions of the four pens which are staggered to permit cross-over along the chart width are marked on each channel. At the chart speed used, however, the parameter leading the change cannot be resolved.

It is of interest to consider the power and thermal balance during this disturbance. From the initial steady-state conditions, the neutralizer keeper voltage decreased an average of 4 volts and the keeper current increased $0.03 \mathrm{~A}$ for a net decrease of 0.83 watt in neutralizer discharge power. The beam current and vaporizer heater power were constant throughout the transient. Neglecting the effects of change in neutralizer floating poten- 
tial, the 0.8 watt decrease in neutralizer discharge power appears too small to justify a $13^{\circ} \mathrm{C}$ drop in vaporizer temperature. Similar transients in which the floating potential varied only 5 volts nevertheless showed the same amount of vaporizer temperature drop. Intentional variations in neutralizer heater power of the order of 3 watts with sma11 variations in keeper voltage at constant keeper current and constant vaporizer power changed the vaporizer temperature only about $1^{\circ} \mathrm{C}$. It appears that the relatively large change in vaporizer temperature observed in figure' 5 was caused by mechanisms other than the changes in externally supplied power. Also, sudden changes in both keeper voltage and floating potential occurred and then corrected themselves spontaneously.

\section{Performance Map}

The durability test was run at a fixed operating point and normally did not permit an examination of thruster characteristics off the set point. Limited mapping of thruster characteristics was performed at approximately 1000 hour intervals to observe any changes in these characteristics with operating time. The results of performance mapping at 6130 and 9030 hours are presented herein. An earlier mapping at 4250 hours is reported in reference 8 .

Cathode keeper current. The effects of varying the cathode keeper current while maintaining a constant beam current of $25 \mathrm{~mA}$ is shown in $\mathrm{fig}-$ ure 6 . The levels and trends in the keeper voltage (fig. 6(a)) and the ion chamber discharge current (fig. 6(b)) at 6130 and 9030 hours were similar. The cathode keeper voltage reached a maximum at a keeper current between 0.35 and $0.4 \mathrm{~A}$. A corresponding minimum in the discharge current occurred at a slightly lower value of keeper current.

The discharge voltage shown in figure $6(\mathrm{c})$ was generally lower at the 9030 hour point. Because discharge voltage was inversely very sensitive to propellant flow rate, it is apparent that the flow was higher at the later time. At both times, however, the trends in discharge voltage as a function of keeper current were similar. The maxima in the discharge voltage corresponded to the minima in the discharge current. Because the beam current was held constant, it follows that the minimum discharge current was required where the discharge voltage, and hence the ionization, was a maximum.

Discharge current. The effects of varying discharge current are shown in figure 7 . The cathode keeper current was maintained at $0.3 \mathrm{~A}$. No cathode heater power was used. The beam current characteristic curves (fig. $7(\mathrm{a})$ ) at 6130 and 9030 hours were almost identical except for a more rapid fall-off in the later curve at discharge currents below $0.4 \mathrm{~A}$.

The accelerator drain current shown in figure 7 (b) decreased with increasing discharge current. This effect is attributable to less charge exchange ions as beam current and propellant utilization efficiency increased. The higher drain current at 9030 hours was probably due to a slightly higher propellant flow rate.

The discharge voltage shown in figure 7 (c) was about 1.5 volts lower at the 9030 hour point be- cause of the higher propellant flow rate. At discharge currents less than $0.4 \mathrm{~A}$, the drop in discharge voltage below 37 volts and the loss in ionization probably caused the rapid fall-off in beam current (fig. 7(a)). In contrast, the discharge voltage at the 6130 hour point was 37 volts or higher for discharge currents as low as $0.25 \mathrm{~A}$.

Accelerating potentials. The variations in discharge parameters and accelerator drain current with changes in the net accelerating voltage (i.e., changes in specific impulse) and the accelerator potential were relatively minor and consistent with trends reported previously. As ion extraction improved with increasing total accelerating potential difference, the discharge current and voltage required to maintain the design beam current decreased slight1y. Accelerator drain current remained nearly constant or increased slightly with increases in either the net accelerating or accelerator potentials.

Neutralizer keeper current. The gradual rise with time in keeper voltage and neutralizer floating potential for fixed point operation has been shown in the test history (fig. 3 ). The effects of varying neutralizer keeper current are shown in figure 8 . The keeper voltage generally decreased as keeper current was increased (fig. 8(a)). Increasing the heater power also reduced the keeper voltage, but the effects were dependent on the number of operating hours. At 6130 hours, the neutralizer could be operated with no heater power. At 9030 hours, this was no longer possible. At 7100 hours, 10 watts of heater power reduced the keeper voltage below the 6130 hour values. With 10 watts of heater power at 9030 hours, the keeper voltage was still higher than at 6130 hours with no heater power.

It is interesting to note that at 9030 hours the neutralizer could be operated at a given level of keeper voltage if the 5 watts reduction in heater power were compensated by a comparable increase in keeper discharge power. This balance indicates that some minimal temperature is required for neutralizer operation at a given keeper voltage but that the required temperature varies with operating time.

Although the basic design was identical, the thruster cathode showed essentially no change with time (fig. 3), and it was operable throughout the test with no heater power. The one major difference between the neutralizer and the cathode was the level of mercury flow rate. The cathode operated in the region of $33-35 \mathrm{~mA}$ equivalent; the neutralizer, in the region of 1.7 to $2.5 \mathrm{~mA}$.

The corresponding variations in neutralizer floating potential are shown in figure $8(\mathrm{~b})$. The floating potential increased rapidly as keeper current was reduced below a critical "knee" value. The "knee" value of keeper current was also dependent on heater power level and operating time. Higher heater power moved the knee to lower values of keeper current. For most of the test, the keeper current was held at $0.45 \mathrm{~A}$ which was well above the critical value for all conditions. In general, the combination of heater power level and operating time which affected keeper voltage had similar effects upon the floating potential. 
Performance profiles and thruster operating parameters at 6130,9030 , and 9700 hours are given in table I. The relatively constant thruster operation indicated by the test history is reflected in the power values. Beam power, discharge power, accelerator drain, and total cathode power were nearly constant throughout the test.

The major change in total input power with time was due to the increase in neutralizer heater power required to permit unattended stable operation of the neutralizer. Because of thermal feedback to the vaporizer, higher heater power was partially offset by a lower vaporizer power requirement to maintain a constant temperature. Total input power thus increased about 9 watts by the end of test to cause a 5 percent drop in power and overall efficiency. Specific impulse varied slightly because of differences in total propellant utilization efficiency. Power to thrust ratio increased by about 20 watts per mlb.

\section{Post-Shutdown Inspection}

Electrostatic vector grid. Figure 9 is a photograph of the thruster in vertical position taken immediately after retraction from the vacuum test facility. The broken vector grid element which caused the decision to terminate the test is in visible contact with the opening in the ground screen mask. The ground screen and adjacent outside structures were remarkably clean and free of any loose metallic deposits.

A photograph of the vector grid taken from the screen or ion chamber side is shown in figure 10 . Care was taken to remove the grid assembly in a vertical position to minimize jarring and disturbing the flakes. Flakes can be seen lying in the peripheral regions of the screen grid and the magnetic pole piece.

A comparison of the flake locations and the eroded vector grid elements indicated that anomalous erosion was caused by flake-diverted beam ions. A more gradual type of erosion was caused by highly divergent ions from each beamlet hole and particularly from the 12 outermost holes.

Figure 11 is a photograph taken from the accelerator side of the vector grid. The broken grid element has been removed. Five grid elements were eroded through, but only one element (shown removed) dropped completely out of position. The others were either restrained from falling by the charge-exchange protective shields or held by the orthogonal elements lying cross-wise above them.

Numerous darkened areas outside the hole pattern can be seen on the face of the screen grid. These were arc sites formed where capacitor discharges were used to clear a short between the screen and accelerator. Sputtered metal, probably from the neutralizer, was deposited in those regions not shielded by the ground mask.

Neutralizer. A close-up photograph of the neutralizer taken after the test is shown in figure 12. The double layer of $0.0127 \mathrm{~mm}$ thick tantalum foil used as an erosion rate detector marks the approximate boundary of the intercepted ion beam. The boundary lay on a 45 degree line drawn from the trailing edge of the outermost beam hole grid element. The tantalum foil eroded at a rate of only 13 microns per 500 to 600 hours of undeflected beam operation. The maximum depth of erosion on the neutralizer keeper cap is estimated to be 250 to 300 microns at the corner which projected most deeply into the ion beam.

A photograph of the neutralizer hollow cathode is shown in figure 13. Erosion occurred at the aperture and the chamfered surface of the tip. An enlarged drawing of the tip disk sectioned along a diameter is shown in figure 14. The dotted outline shows the aperture size and the chamfered surface when new. During 9715 hours of operation the aperture eroded from 0.254 to $0.549 \mathrm{~mm}$ at the neck.

Preliminary data taken by A. Weigand of LeRC has indicated that neutralizer tip erosion can be a strong function of neutralizer flow rate. Simulation of total depletion of the insert's emissive coating by operating cathodes without any insert or emissive coating has shown that erosion of the tip will take place at the flow rates used during this endurance test. Weigand's data has indicated that for $5 \mathrm{~cm}$ neutralizer flow rates at or above $6.9 \mathrm{~mA}$ the tip erosion rate is reduced by over 2 orders of magnitude even if the insert has been totally depleted. Thus neutralizer operation at slightly higher flow rates, with a small penalty on propellant utilization efficiency, appears to be an attractive operating mode to prevent excessive tip erosion.

Neutralizer insert. The neutralizer insert was examined for possible correlation between neutralizer operation and insert condition. Figure $\mathbf{1 5}$ is a photograph of the insert after it was unrolled and stretched out. Parts of the downstream edge (nearest the neutralizer tip) of the insert appeared to have reached high enough temperatures to cause embrittlement and erosion. These regions were either sintered layer-to-layer or so brittle that crumbling occurred. The upstream portion of the insert remained intact and springy. A small rod was required to keep the insert from recoiling.

Both the upstream and downstream regions of the insert were examined with an optical microscope and an electron scanning microscope with elemental identification by an energy dispersive analyzer. Barium was detected generally in the upstream region, but the downstream edges were practically devoid of barium except in small isolated or sheltered regions. The conclusion is that an ample amount of the barium emissive mixture was left in the insert, but it was not available or present in localized areas where required for good neutralizer operation.

Cathode pole assemb1y and thruster back plate. A photograph of the cathode pole assemb1y and thruster back plate which were exposed to the ion chamber plasma is shown in figure 16. The extent of erosion can be seen by comparison with figure 17 which is a photograph of the same component after 2027 hours of operation. The magnification was higher so that the initial stages of erosion could be seen around the screw threads and the hexagonal corners of the nut.

After 9715 hours, a11 but 0.009 gram of the nut (original estimated weight, $0.099 \mathrm{gm}$ ) was 
eroded. 0nly two threads of the 0-80 stainless steel screw remained above the baffle. The baffle itself was only slightly eroded at the downstream peripheral edge.

Slight erosion was found on the thruster back plate. Four radial traverses were made with a surface analyzer to determine the depth of surface erosion. Although not axially symmetrical the maximum erosion was about 8 microns at a radius of about $2 \mathrm{~cm}$.

J. Power and E. Wintucky of LeRC have proposed the use of pyrolytic graphite coatings over cathode potential surfaces to reduce the sputtering of these components. The low sputter yield of carbon should greatly reduce the material loss rates from cathode potential surfaces. Tests of pyrolytic graphite baffles and thruster back plates are currently being performed to evaluate these sputter resistant components.

Anode. A photograph of the ion chamber interior looking from the cathode end is shown in figure 18. The anode showed no sign of erosion. Peeling of sputtered metal which formed the flakes was evident around most of the upstream end of the anode. It is believed that the main source of sputtered metal was the baffle assembly and the thruster back plate. The flakes which peeled off were typically $0.021 \mathrm{~mm}$ thick and magnetic.

The exact cause of peeling is not known. Thermal cycling because of thruster shutdowns, the mismatch of expansion coefficients, exposure to atmospheric moisture at $2027 \mathrm{hr}$, and the mechanical stability limit of sputtered material probably all contributed to the loosening of an already weakly bonded layer.

It has been proposed that an opaque finely woven screen anode would retard the peeling off of sputter deposited material on the anode. Conceptually, the sputter deposited films would have thickness variations around each wire of the woven anode. At points where two wires cross or contact each other the film thickness should be near zero. As a result of the woven anode structure, all sputtered film patches are surrounded by near zero thickness films. Thus, even if a sputter deposited film cracks or peels in the region of thickest deposition, the flakes should remain attached at the places where the film is thin and strongly adherent. If the screen anode is finely woven the distances between maximum and minimum film thicknesses are small, thus reducing the probability of flakes totally detaching from their thinner surrounding regions. Tests of the screen anode are being made to determine its effectiveness in the prevention of loose flakes. The combination of reduction in sputter rate of the cathode potential surfaces and the peel resistant anode could prevent formation of loose flakes.

\section{Concluding Remarks}

A five centimeter diameter mercury bombardment ion thruster has been life tested for 9715 hours. The test was interrupted once at 2027 hours to replace the translatable screen thrust vector grid with an electrostatic type.

During the final 2715 hours of the test, the cathode and ion chamber discharge characteristics were essentially the same as those observed earlier in the test. Comparison of thruster performance profiles taken during the lifetest showed that overall efficiency dropped $4 \%$ and power to thrust ratio increased $19 \mathrm{w} / \mathrm{mlb}$. The principal cause of these changes was the increase in neutralizer heater power required for stable operation. Proposed solutions to avoid neutralizer performance changes are present1y being life tested.

Accelerator drain current increased significantly only after sputtered metal flakes shed from anode surfaces fell upon the screen grid of the ion accelerator system. Beam diversion from partially blocked screen holes increased direct ion impingement and eventually eroded thrust vectoring grid elements. Electrical shorting of the grid increased in number and frequency as the test progressed. All shorts were successfully cleared either by steady application of power or by a capacitor discharge.

Post-test inspection showed varying degrees of erosion of the grid elements, neutralizer tip, cathode baffle assembly, and thruster back plate. Examination of the neutralizer insert showed depletion of the barium emissive mixture at the downstream edge nearest the neutralizer tip. Substantial amounts of barium were found on all upstream areas of the insert.

Except for the electrostatic type vector grid, no other thruster component indicated imminent failure at 9715 hours.

Table 1 Performance profile

$\begin{array}{lrrr}\text { Test hours } & 6130 & 9030 & 9700 \\ \text { Net accelerating potential, V } & 1300 & 1300 & 1300 \\ \text { Accelerator potential, V } & -900 & -900 & -900 \\ \text { Beam current, mA } & 25 & 25 & 25 \\ \text { Cathode flow rate, mA equiv } & 32.1 & 33.0 & 33.4 \\ \text { Neutralizer flow rate, mA equiv } & 2.2 & 2.2 & 2.4 \\ \text { Beam power, w } & 32.5 & 32.5 & 32.5 \\ \text { Discharge power, w } & 15.9 & 16.6 & 16.3 \\ \text { Component power } & & & \\ \text { Accelerator drain, w } & 0.18 & 0.2 & 0.28 \\ \text { Cathode } & 0 & 0 & 0 \\ \quad \text { Heater, w } & 4.37 & 3.76 & 3.78 \\ \text { Keeper discharge, w } & 5.53 & 5.16 & 5.76 \\ \quad \text { Vaporizer, w } & 9.90 & 8.92 & 9.54 \\ \quad \text { Total cathode power, w } & & & \\ \text { Neutralizer } & 2.40 & 9.90 & 9.90 \\ \quad \text { Heater, w } & 8.90 & 10.90 & 9.98 \\ \text { Keeper discharge, w } & 1.16 & 0.32 & 0.42 \\ \quad \text { Vaporizer, w } & 12.46 & 21.12 & 20.30 \\ \quad \text { Total neutralizer power, w } & 70.9 & 79.3 & 78.9 \\ \text { Total input power, w } & 45.9 & 41.0 & 41.2 \\ \text { Power efficiency, \% } & 73.0 & 71.1 & 69.8 \\ \text { Utilization efficiency, \% } & 33.5 & 28.1 & 28.8 \\ \text { Overall efficiency, \% } & 0.41 & 0.41 & 0.41 \\ \text { Thrust, mlb } & 2630 & 2560 & 2515 \\ \text { Specific impulse, sec } & 173 & 193 & 192 \\ \text { P/T ratio, w/mlb } & & & \end{array}$




\section{REFERENCES}

1. Owens, W. L., Jr., "Optimization of Ion Propulsion for North-South Stationkeeping of Communications Satellites," Paper 72-1150, Nov. 1972, AIAA/SAE, New Orleans, La.

2. Hudson, W. R., and Banks, B. A., "An $8 \mathrm{~cm}-$ Electron Bombardment Thruster for Auxiliary Propulsion," Proposed Paper, Oct.-Nov. 1973, AIAA, Lake Tahoe, Nev.

3. Isley, W. C., and Duck, K. I., "Propulsion Requirements for Communications Satellites," Paper 72-514, Apr. 1972, AIAA, New York, N.Y.

4. Free, B., and Huson, G., "Selected Comparisons Among Propulsion Systems for Communications Satellites," Paper 72-517, Apr. 1972, AIAA, New York, N.Y.
5. Hyman, J., Jr., "Design and Development of a Small Structurally Integrated Ion Thruster System," NASA CR-120821, Oct. 1971, Hughes Research Labs., Malibu, Calif.

6. King, H. J., Collett, C. R., and Schnelker, D. E., "Thrust Vectoring Systems. Part I: $5-\mathrm{cm}$ Systems," NASA CR-72877, 1970, Hughes Research Labs., Malibu, Calif.

7. Nakanishi, S., and Finke, R. C., "A 2000-Hour Durability Test of a 5-Centimeter-Diameter Mercury Bombardment Ion Thruster," TM X-68155, 1972, NASA, Cleveland, Ohio.

8. Nakanishi, S., "Durability Tests of a 5Centimeter-Diameter Ion Thruster System," Paper 72-1151, Nov. 1972, AIAA/SAE, New Orleans, La. 


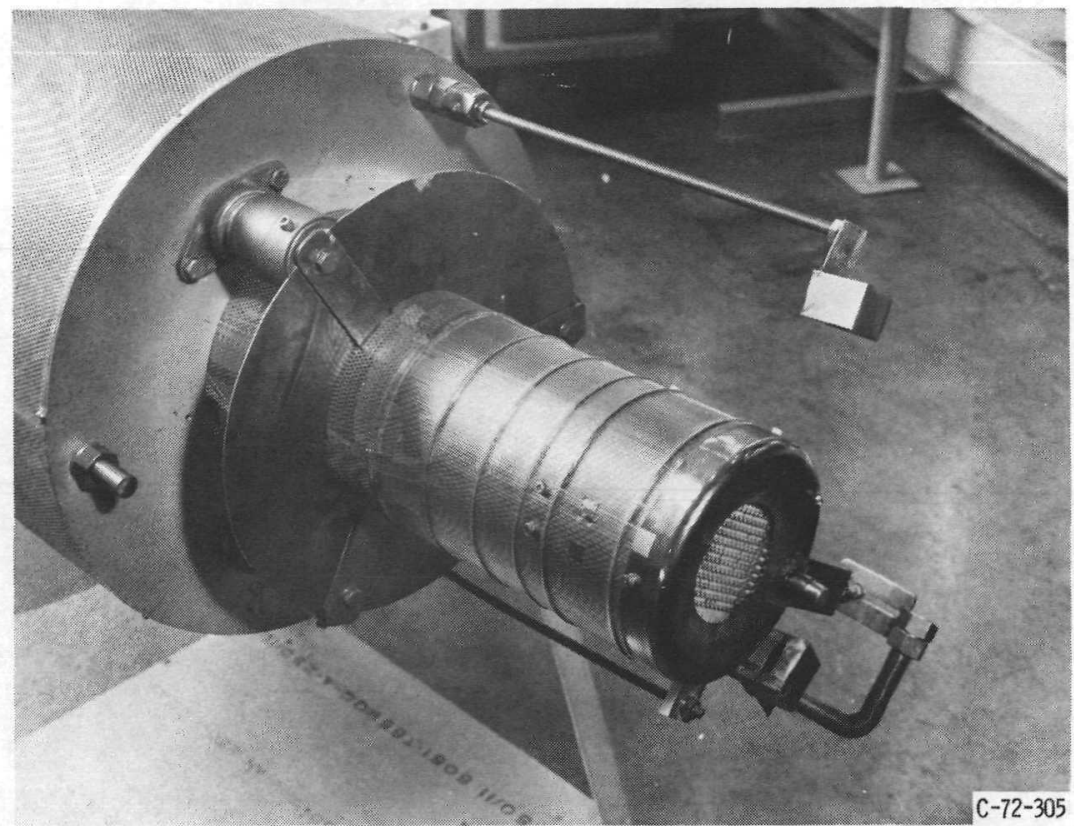

Figure 1. - Test installation of modified SIT-5 thruster.

虫

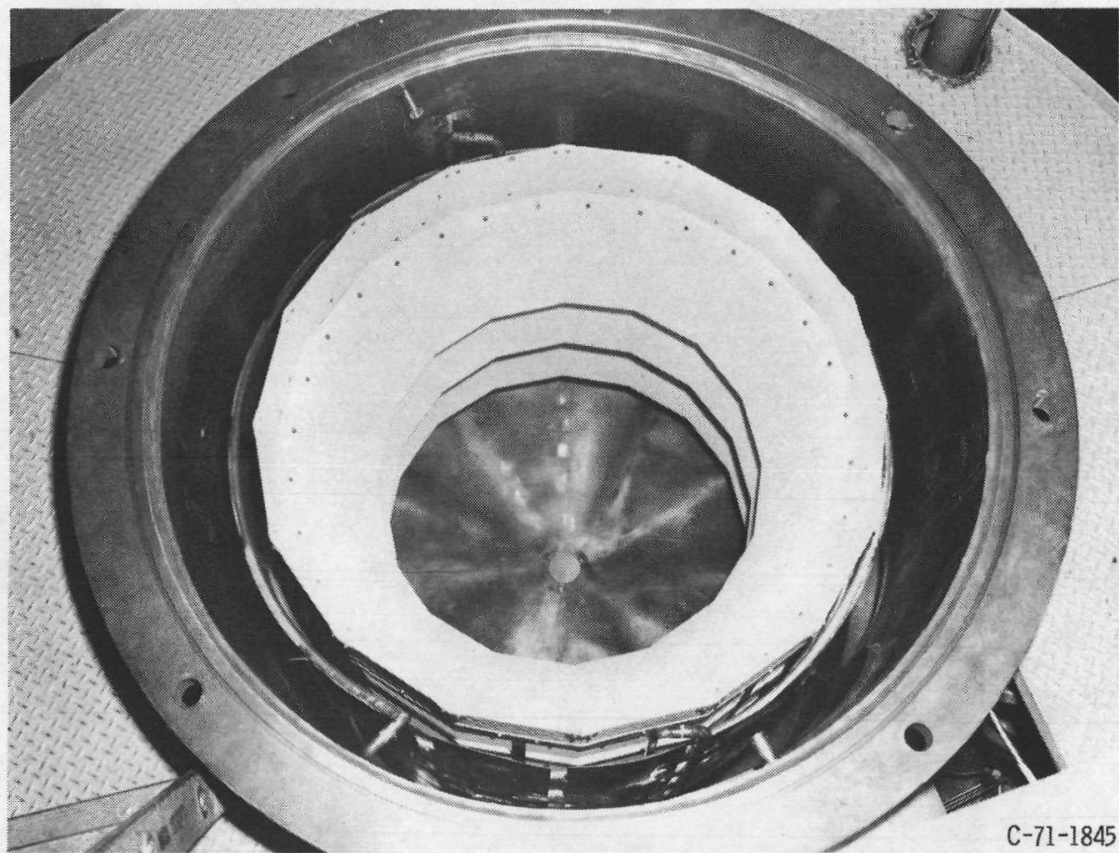

Figure 2. - Tank interior before test. 
LEGEND OF EVENTS

A. NEUTRALIZER OUTAGE

B. HIGH NEUTRALIZER FLOATING POTENTIAL

C. VECTOR GRID SHORT

D. SCREEN-ACCEL SHORT

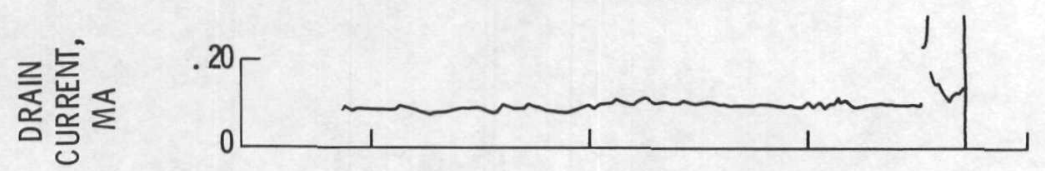

(a) ACCELERATOR DRAIN CURRENT.

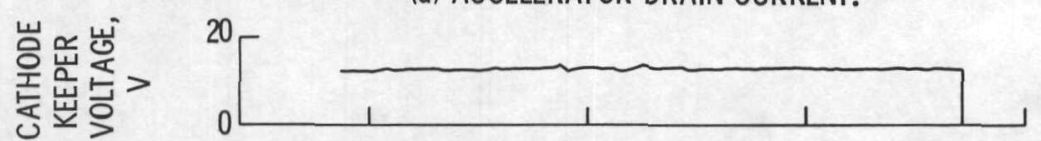

(b) CATHODE KEEPER VOLTAGE. NEUTRALIZER HEATER POWER, W

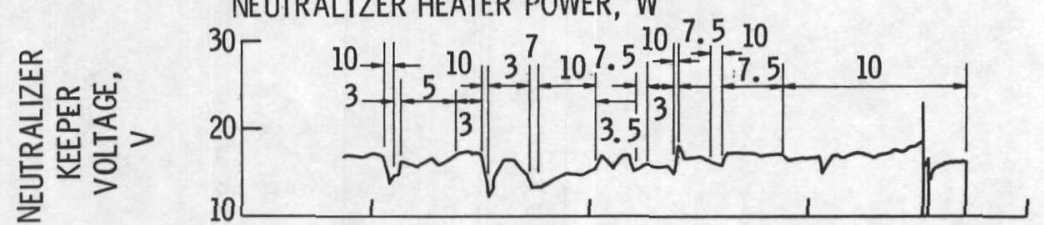

(c) NEUTRALIZER KEEPER VOLTAGE.

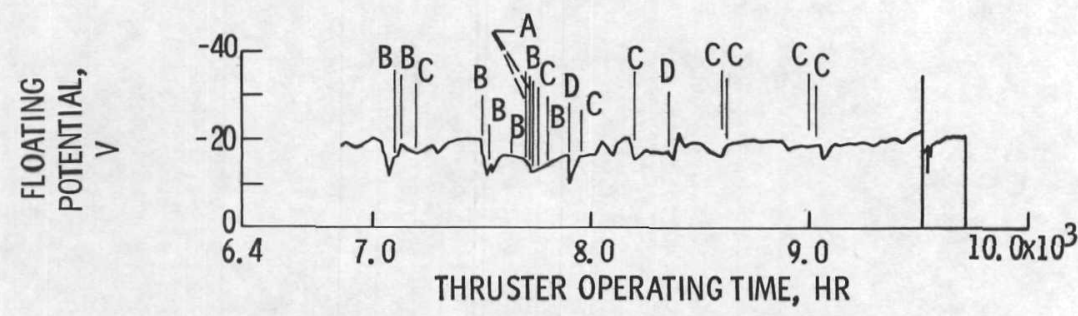

(d) NEUTRALIZER FLOATING POTENTIAL.

Figure 3. - History of test.
LEGEND OF EVENTS

A. NEUTRALIZER OUTAGE

B. HIGH NEUTRALIZER POTENTIAL

C. VECTOR GRID SHORT

D. SCREEN-ACCEL SHORT

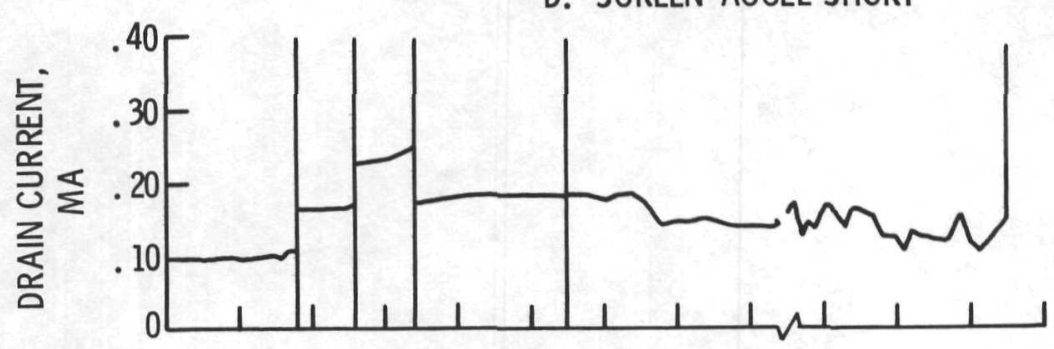

(a) ACCELERATOR DRAIN CURRENT.

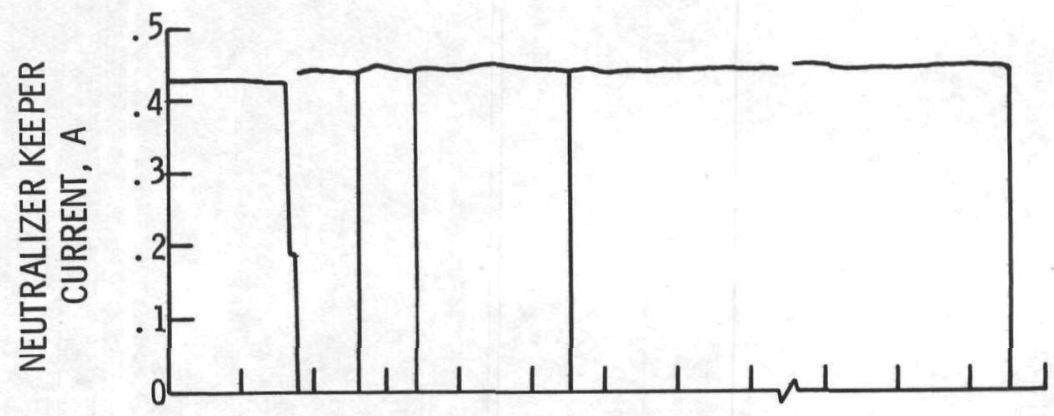

(b) NEUTRALIZER KEEPER CURRENT

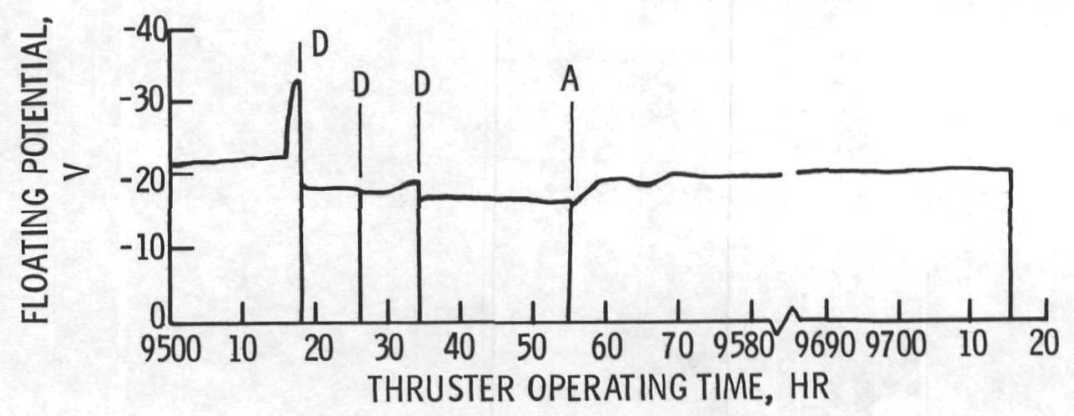

(c) NEUTRALIZER FLOATING POTENTIAL.

Figure 4. - Terminal history of test. 


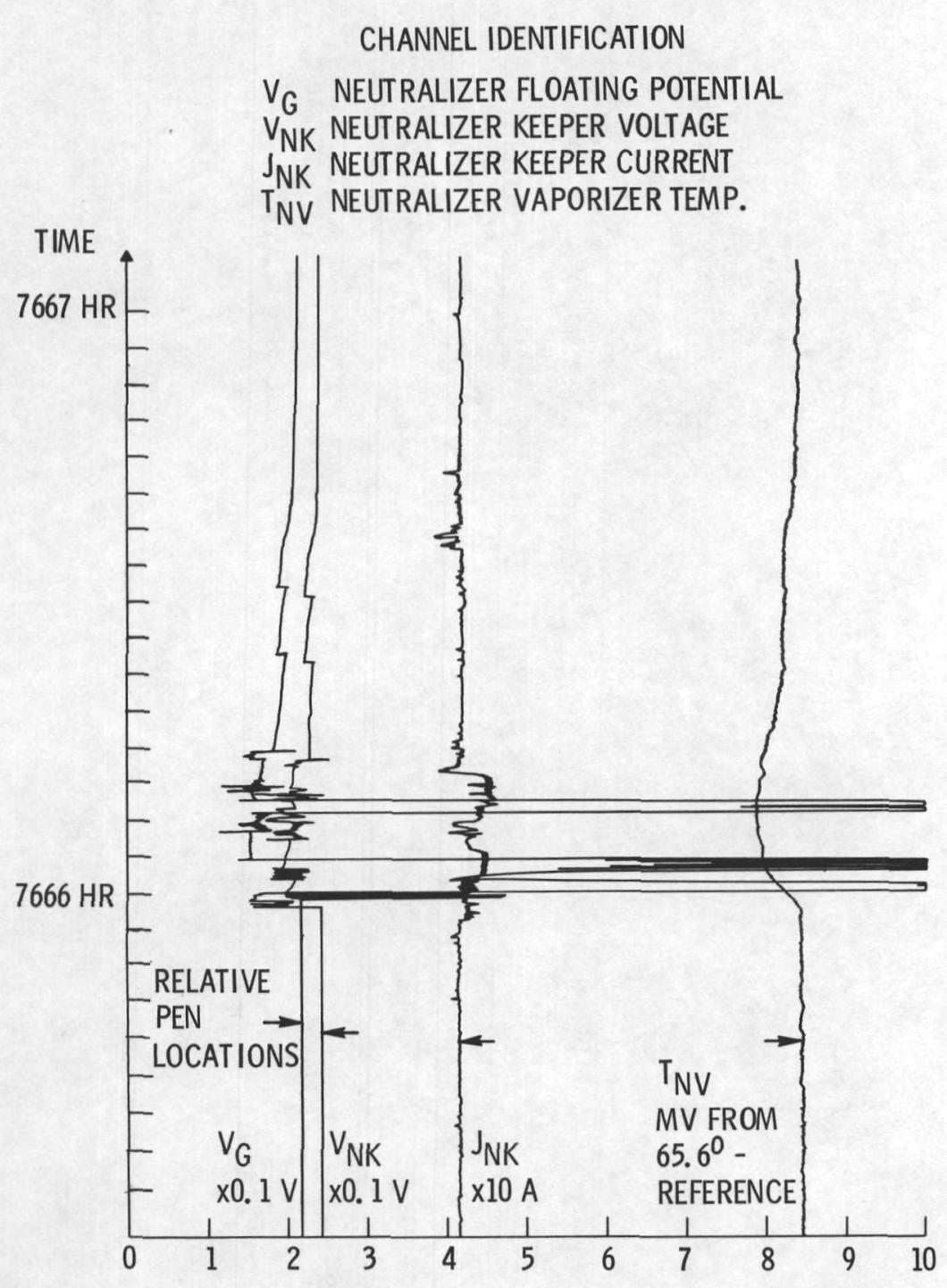

Figure 5. - Strip-chart record of neutralizer parameters.

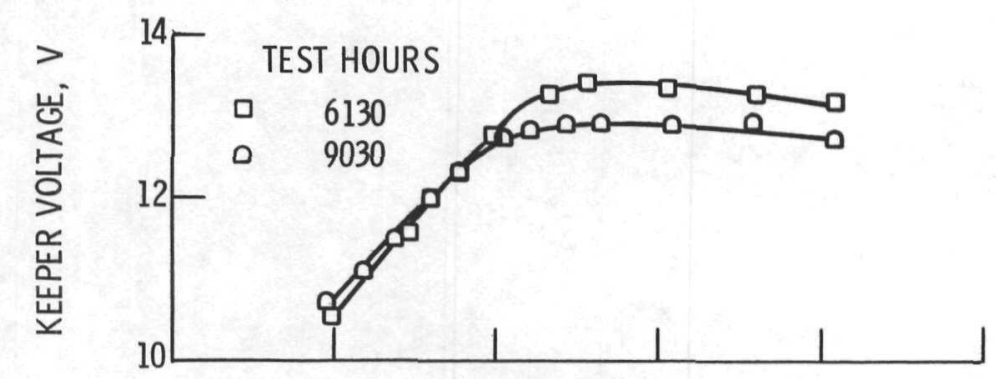

(a) CATHODE KEEPER VOLTAGE.

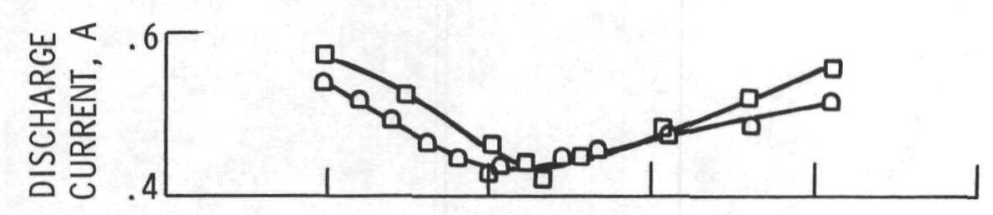

(b) DISCHARGE CURRENT.

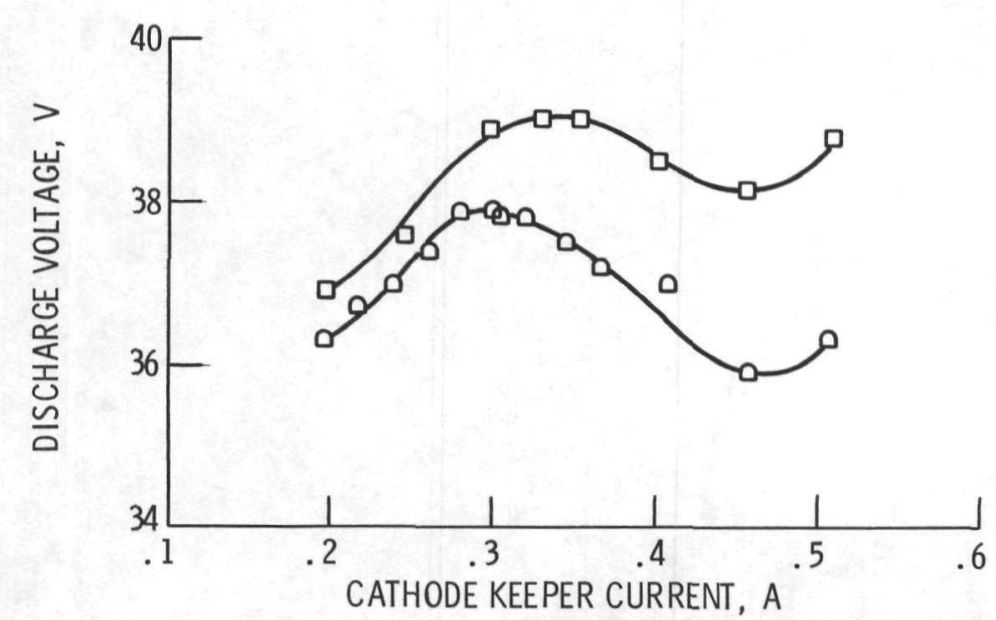

(c) DISCHARGE VOLTAGE.

Figure 6. - Effects of varying cathode keeper current at $25 \mathrm{~mA}$ beam current and no heater power. 


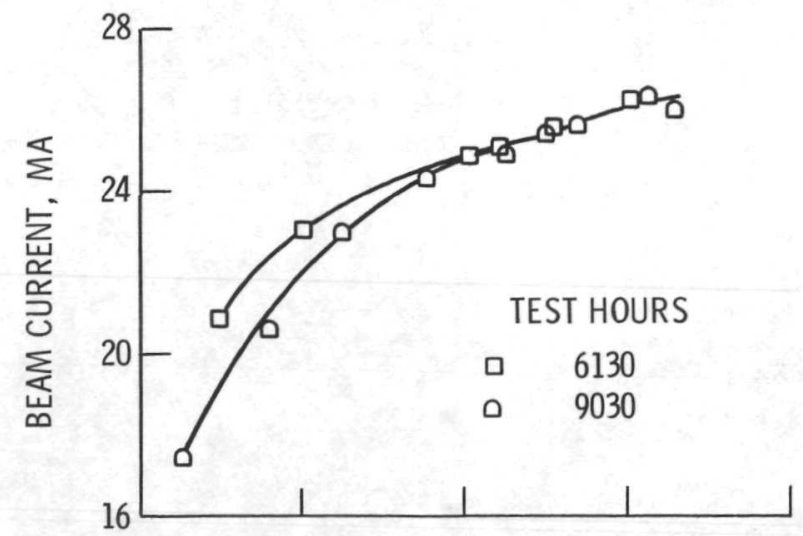

(a) BEAM CURRENT.

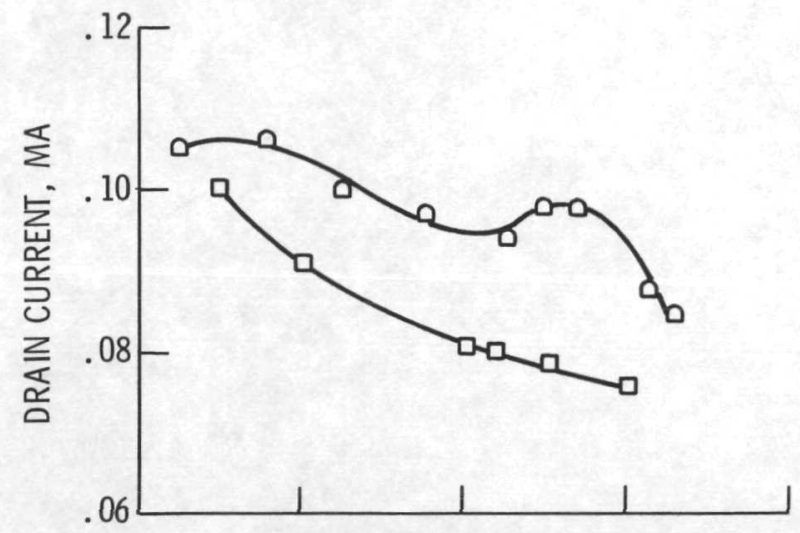

(b) ACCELERATOR DRAIN CURRENT.

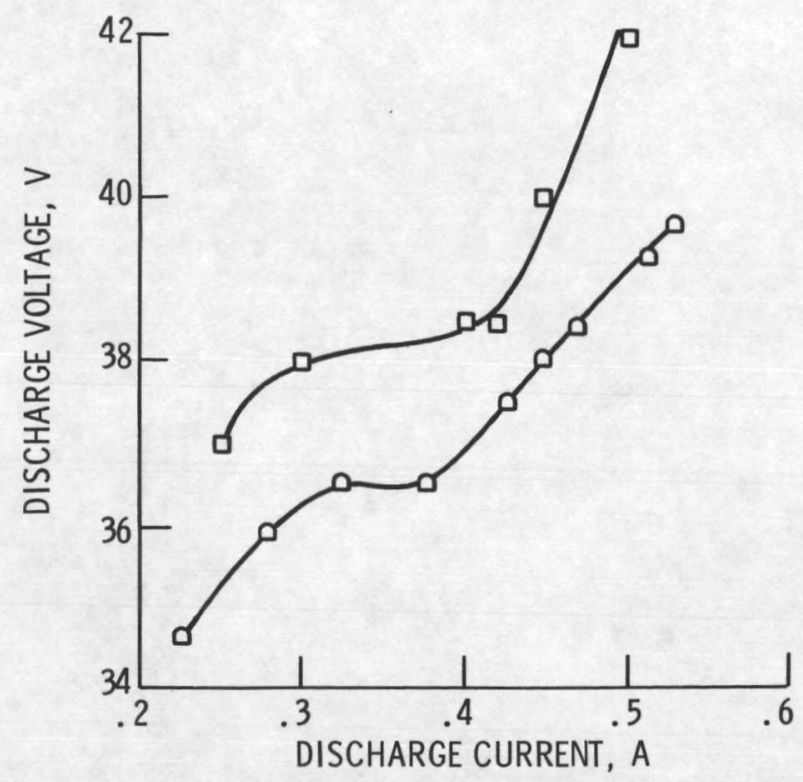

(c) DISCHARGE \OLTAGE.

Figure 7. - Effects of varying ion chamber discharge current. Cathode keeper current, $0.3 \mathrm{~A}$. 


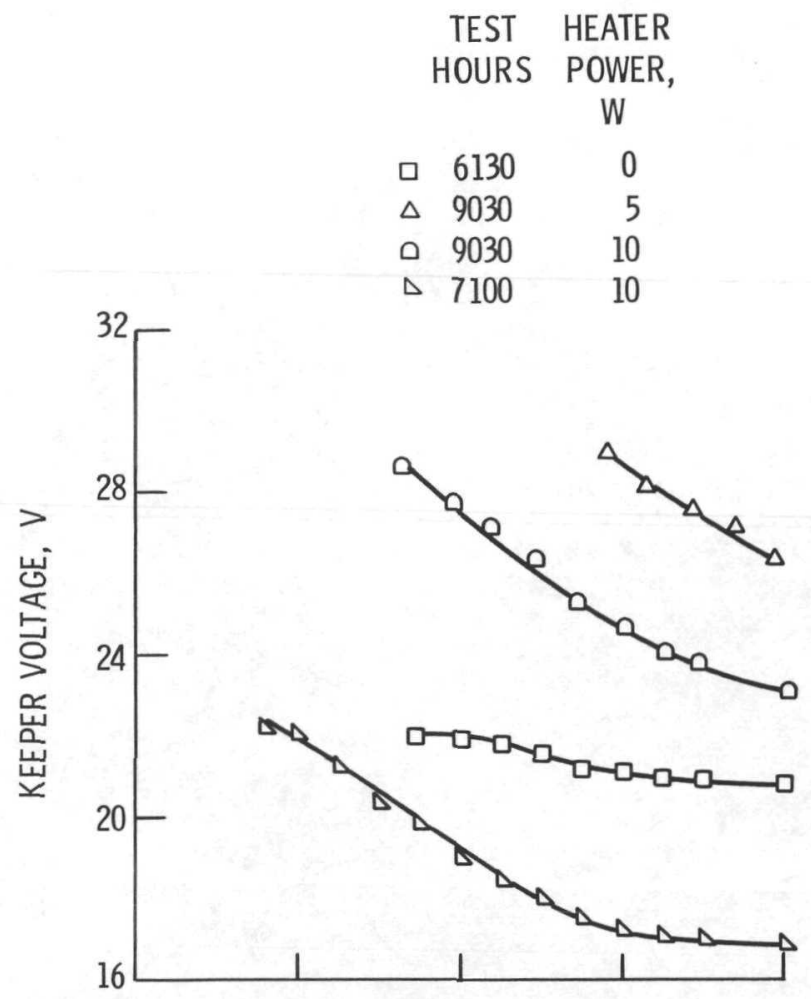

(a) NEUTRALIZER KEEPER VOLTAGE.

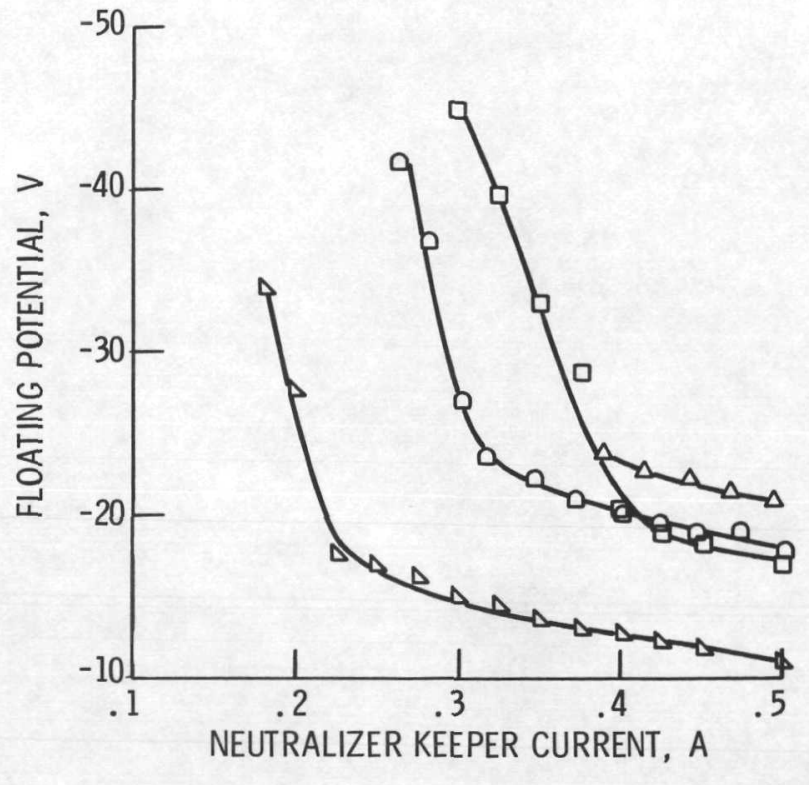

(b) NEUTRALIZER FLOATING POTENTIAL.

Figure 8. - Effects of varying neutralizer keeper current. 


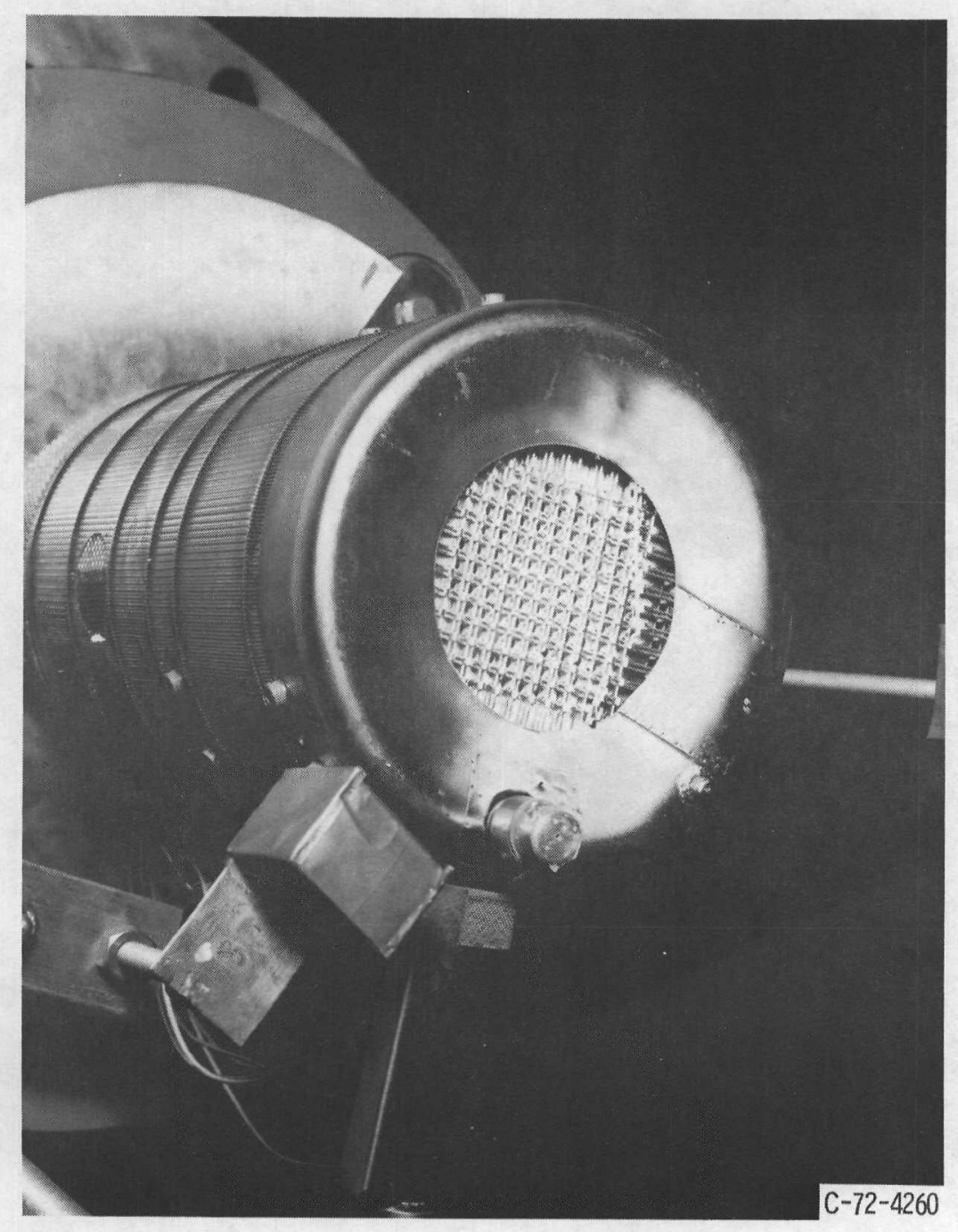

Figure 9. - SIT-5 thruster after test.

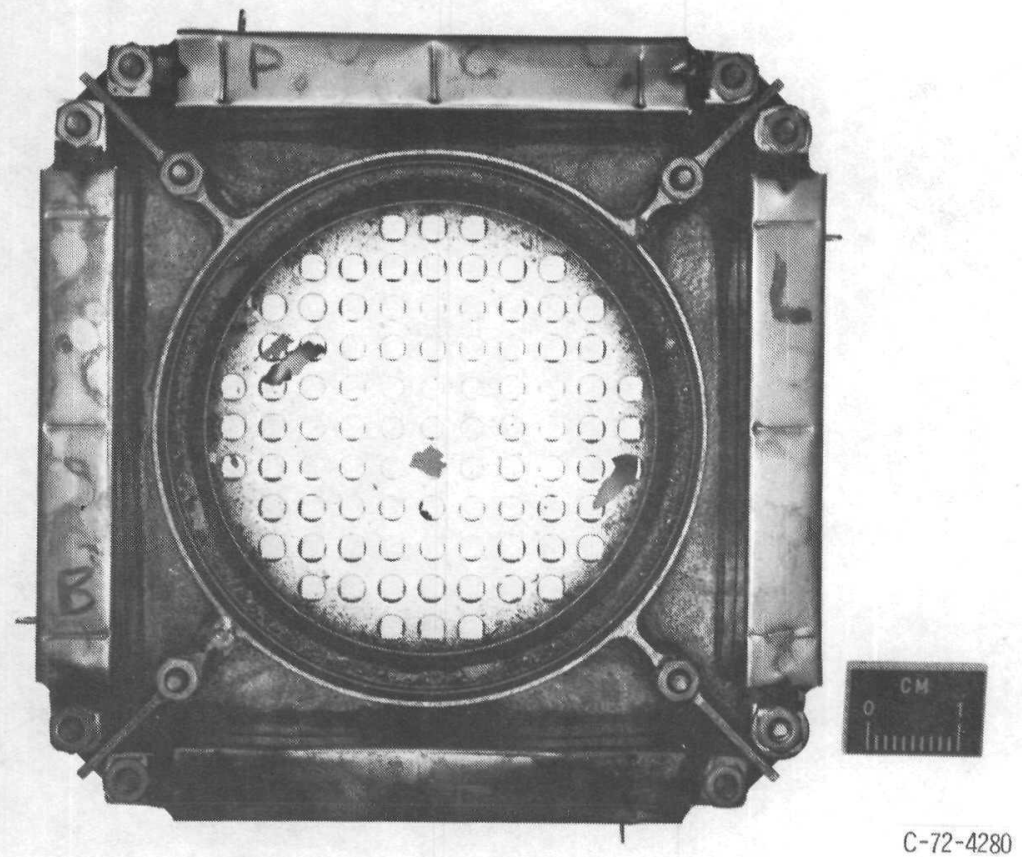

Figure 10. - Electrostatic vector grid after test showing metal flakes on screen electrode. 


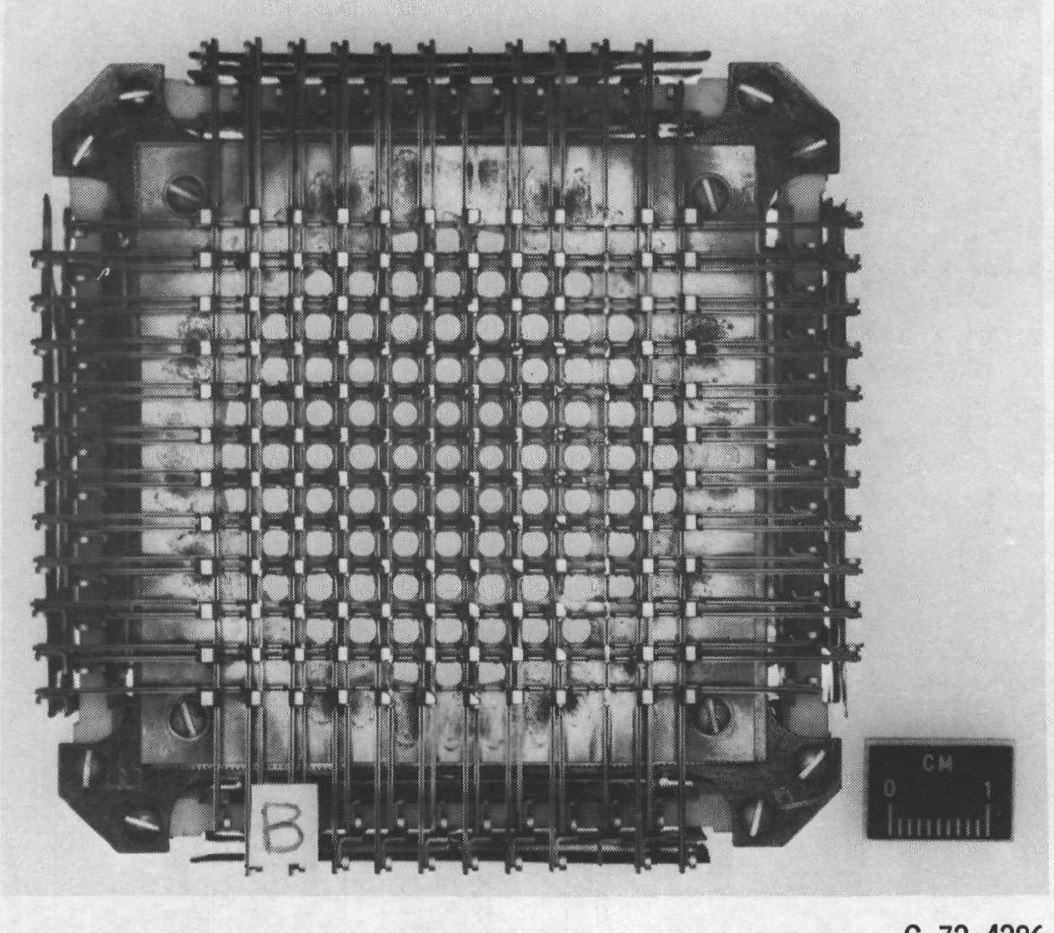

Figure 11. - Electrostatic vector grid after test.

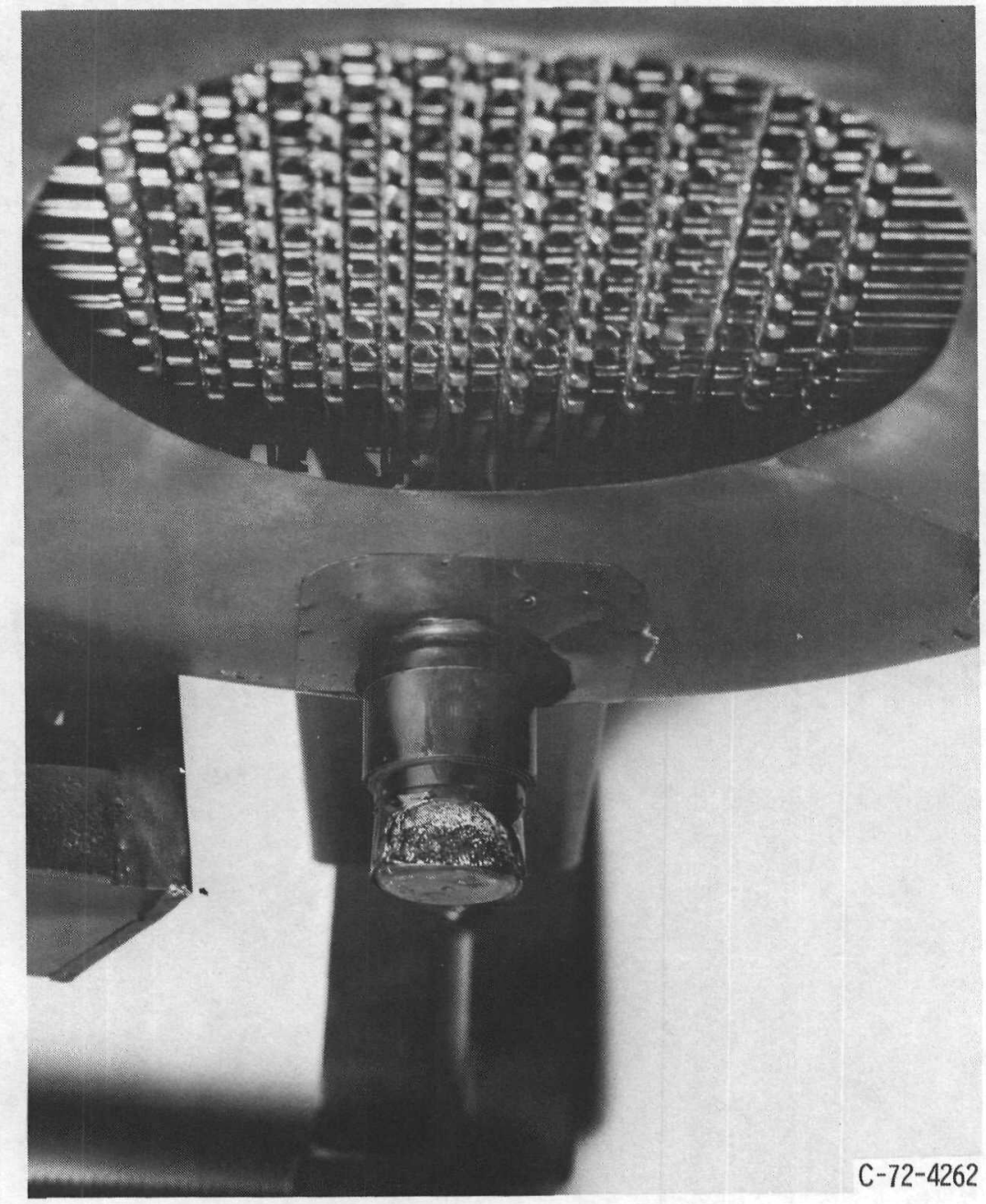

Figure 12. - Neutralizer after test. 


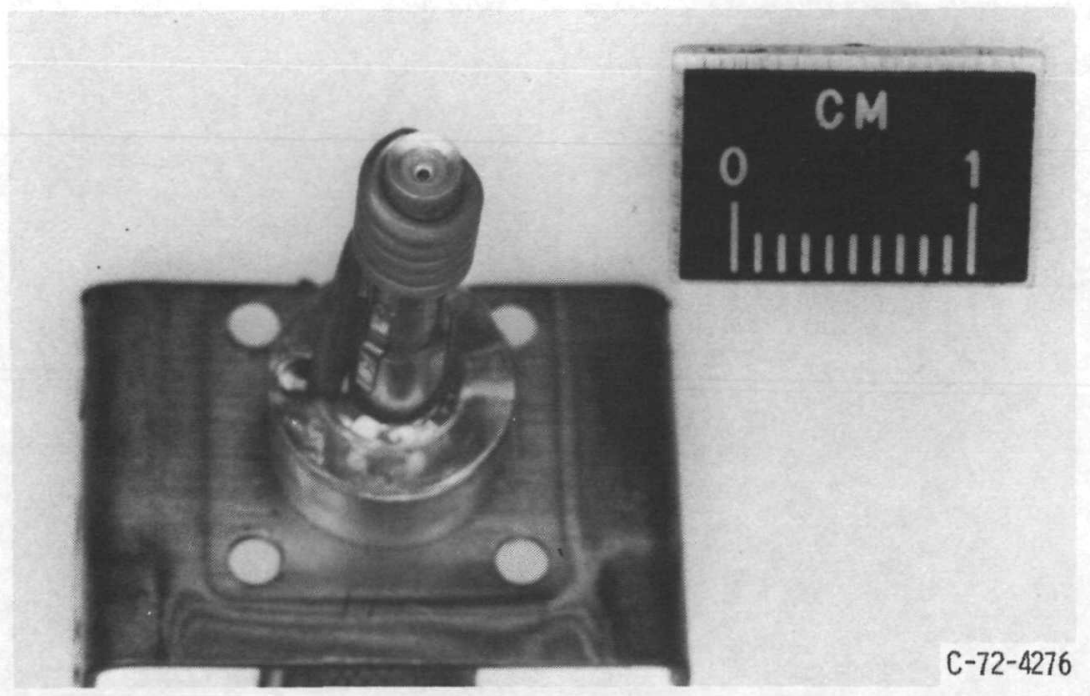

Figure 13. - Neutralizer hollow cathode after 9715 hours.

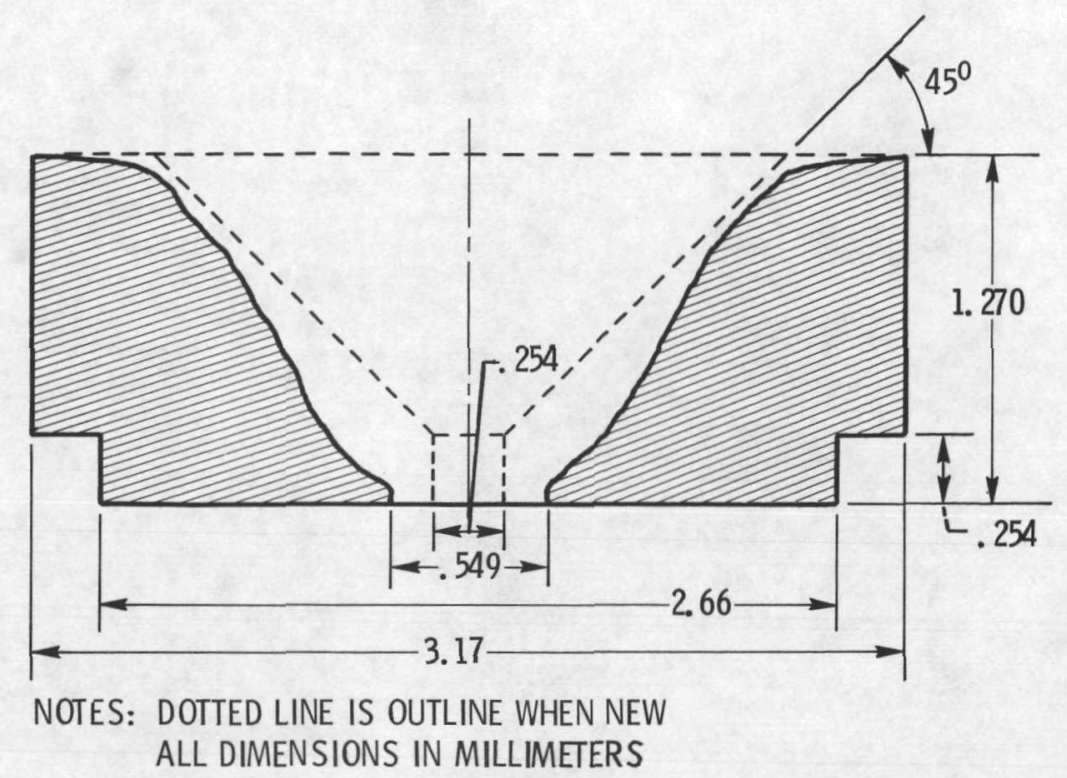

Figure 14. - Cross-section of neutralizer tip disk. 


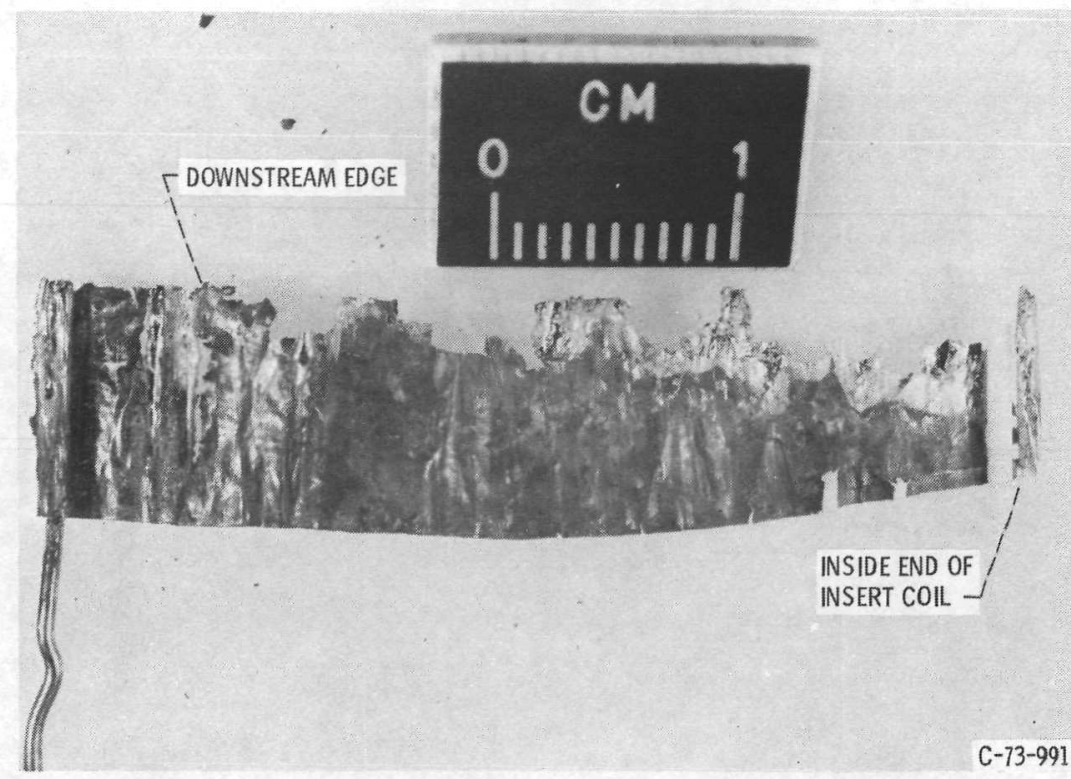

Figure 15. - Unrolled neutralizer insert after 9715 hours.

กै

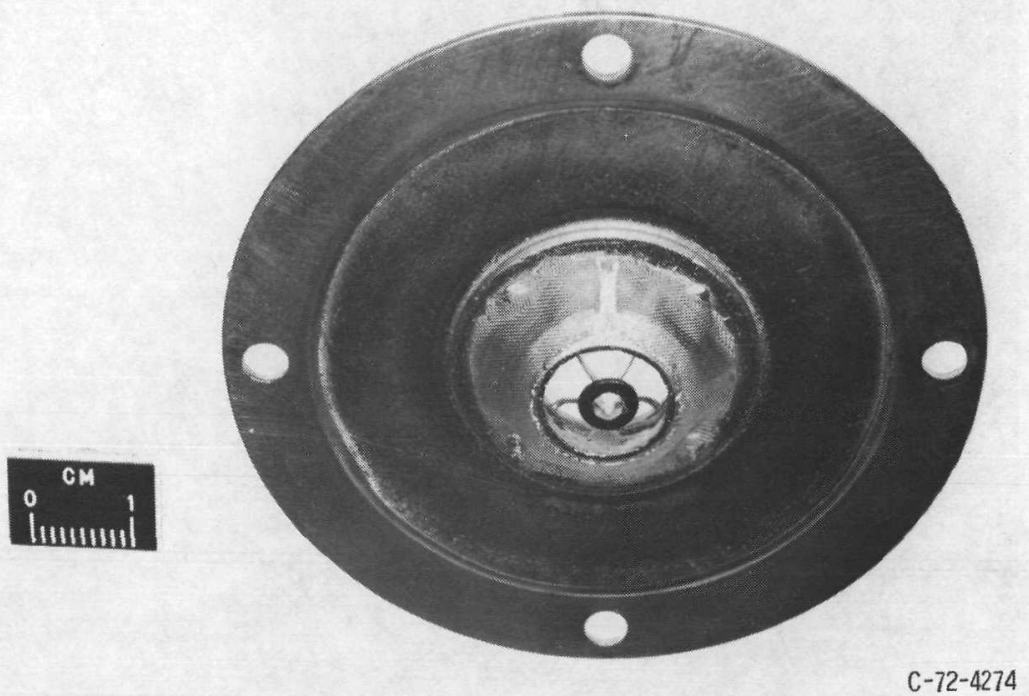

Figure 16. - Cathode pole assembly and thruster back plate after 9715 hours. 


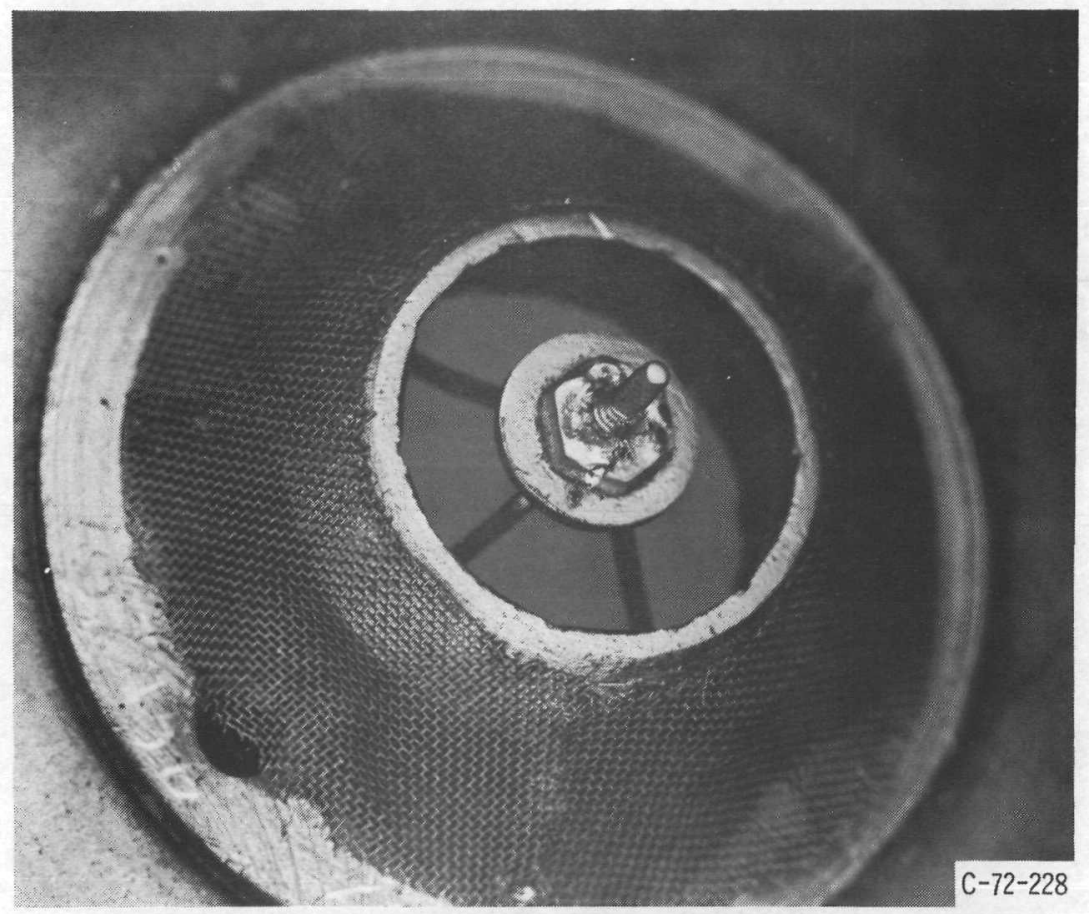

Figure 17. - Cathode pole assembly after 2027 hours.

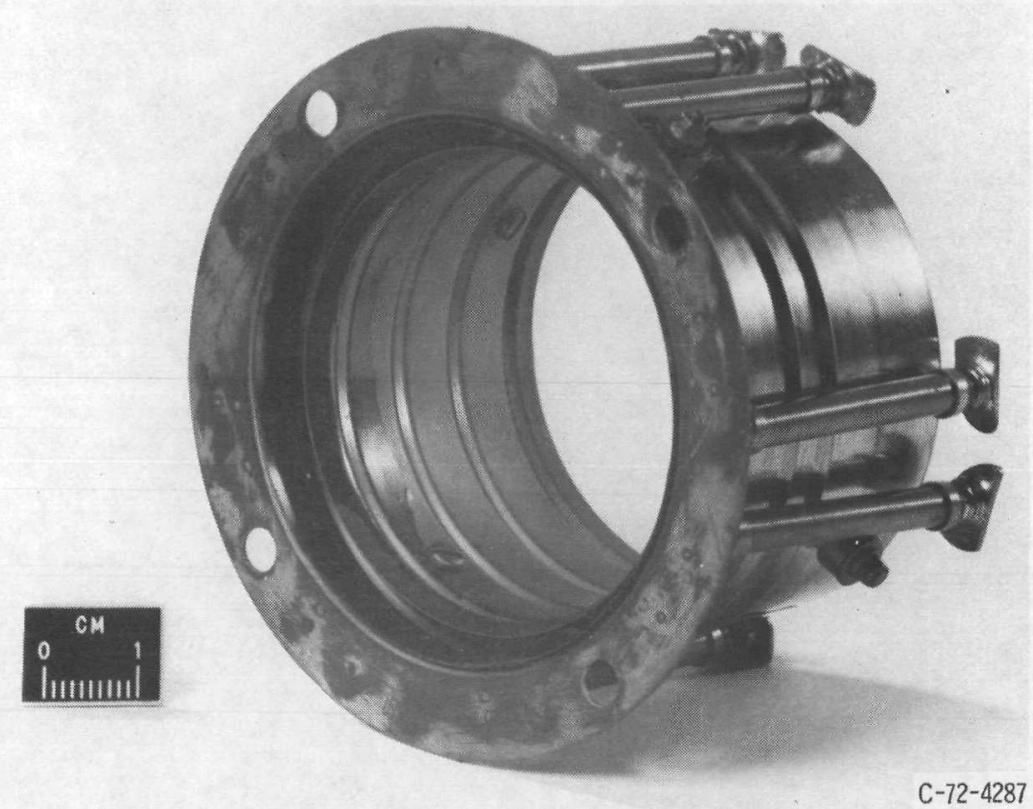

Figure 18. - Anode after 9715 hours. 